British Journal of Nutrition (2021), 126, 773-781

doi:10.1017/S0007114520004705

(C) The Author(s), 2020. Published by Cambridge University Press on behalf of The Nutrition Society. This is an Open Access article, distributed under the terms of the Creative Commons Attribution licence (http://creativecommons.org/licenses/by/4.0/), which permits unrestricted re-use, distribution, and reproduction in any medium, provided the original work is properly cited.

\title{
Characterising percentage energy from ultra-processed foods by participant demographics, diet quality and diet cost: findings from the Seattle Obesity Study (SOS) III
}

Shilpi Gupta ${ }^{1 *}$, Chelsea M. Rose ${ }^{1}$, James Buszkiewicz ${ }^{1}$, Linda K. $\mathrm{Ko}^{2,3}$, Jin Mou ${ }^{4}$, Andrea Cook ${ }^{5,6}$, Anju Aggarwal ${ }^{1}$ and Adam Drewnowski ${ }^{1}$

${ }^{1}$ Center for Public Health Nutrition, Department of Epidemiology, University of Washington, Seattle, WA 98105, USA

${ }^{2}$ Division of Public Health Sciences, Department of Cancer Prevention, Fred Hutchinson Cancer Research Center, Seattle, WA 98109, USA

${ }^{3}$ Department of Health Services, University of Washington, Seattle, WA 98105, USA

${ }^{4}$ MultiCare Institute for Research \& Innovation, Tacoma, WA 98405, USA

${ }^{5}$ Biostatistics Unit, Kaiser Permanente Washington Health Research Institute, Seattle, WA 98101, USA

${ }^{6}$ Department of Biostatistics, University of Washington, Seattle, WA 98195, USA

(Submitted 8 July 2020 - Final revision received 5 October 2020 - Accepted 16 October 2020 - First published online 23 November 2020 )

\section{Abstract}

Higher consumption of 'ultra-processed' (UP) foods has been linked to adverse health outcomes. The present paper aims to characterise percentage energy from UP foods by participant socio-economic status (SES), diet quality, self-reported food expenditure and energy-adjusted diet cost. Participants in the population-based Seattle Obesity Study III ( $n$ 755) conducted in WA in 2016-2017 completed socio-demographic and food expenditure surveys and the FFQ. Education and residential property values were measures of SES. Retail prices of FFQ component foods ( $n 378$ ) were used to estimate individual-level diet cost. Healthy Eating Index (HEI-2015) and Nutrient Rich Food Index 9.3 $\left(\mathrm{NRF}_{9.3}\right)$ were measures of diet quality. UP foods were identified following NOVA classification. Multivariable linear regressions were used to test associations between UP foods energy, socio-demographics, two estimates of food spending and diet quality measures. Higher percentage energy from UP foods was associated with higher energy density, lower HEI-2015 and $\mathrm{NRF}_{9.3}$ scores. The bottom decile of diet cost $(\$ 216 \cdot 4 / \mathrm{month})$ was associated with $67.5 \%$ energy from UP foods; the top decile (\$369.9/month) was associated with only $48.7 \%$ energy from UP foods. Percentage energy from UP foods was inversely linked to lower food expenditures and diet cost. In multivariate analysis, percentage energy from UP foods was predicted by lower food expenditures, diet cost and education, adjusting for covariates. Percentage energy from UP foods was linked to lower food spending and lower SES. Efforts to reduce UP foods consumption, an increasingly common policy measure, need to take affordability, food expenditures and diet costs into account.

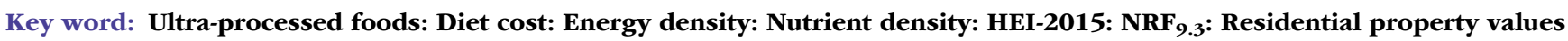

High consumption of 'ultra-processed' (UP) foods as defined by the NOVA classification scheme ${ }^{(1)}$ has been associated with a wide range of adverse health outcomes. Studies have pointed to positive associations between percentage energy from UP foods and risk of excess weight gain ${ }^{(2,3)}$, obesity ${ }^{(4)}$, diabetes ${ }^{(5)}$, the metabolic syndrome ${ }^{(6)}$, hypertension ${ }^{(7)}$, depressive symptoms ${ }^{(8,9)}$, incident frailty ${ }^{(10)}$, cancer $^{(11)}$ and all-cause mortality $^{(12,13)}$. The global obesity pandemic ${ }^{(14)}$ was blamed on the rising consumption of industrial UP foods.

What many UP foods seem to have in common is low per energy cost ${ }^{(15)}$. In one study based on FFQ component foods ${ }^{(15)}$,
UP foods cost $\$ 0.55$ per $418 \mathrm{~kJ}$ compared with $\$ 1.45 / 418 \mathrm{~kJ}$ for minimally processed foods. A clinical study ${ }^{(2)}$ reported that the ingredients for $8368 \mathrm{~kJ} / \mathrm{d}$ of UP meals cost $\$ 106 /$ week, whereas unprocessed meals cost as much as $\$ 151 /$ week or $42 \%$ more, based on food prices at a local supermarket chain. The monetary cost of observed diets with high percentage of energy from UP foods still remains to be explored. None of the cited studies on the links between UP foods and health outcomes has addressed the relative affordability of UP foods relative to healthier and more 'prudent' options, a fundamental issue in all studies of social disparities, diets and health.

Abbreviations: HEI-2015, Healthy Eating Index 2015; NRF ${ }_{9.3}$, Nutrient Rich Food Index 9.3; SES, socio-economic status; SOS III, Seattle Obesity Study III; UP, ultra-processed.

* Corresponding author: Shilpi Gupta, email shilpi24@uw.edu 
It is by now well established that food prices and diet costs contribute to the observed socio-economic disparities in diet quality and may affect health outcomes ${ }^{(16-19)}$. Low-cost energy-dense foods composed of refined grains, added sugars and added fats are generally more affordable than are the recommended diets of minimally processed lean meats and fish, fresh vegetables and fruit, or home-made pasta and bread ${ }^{(16,17)}$. The observed associations between lower socio-economic status (SES) and higher rates of obesity and other noncommunicable diseases may be mediated, in part, by the low-cost and high reward value of processed energy-dense foods ${ }^{(16-19)}$.

The present analysis used data from the Seattle Obesity Study III (SOS III) to link percentage energy from UP foods to two measures of food spending: self-reported food expenditures and estimated individual-level diet costs. We expected that percentage energy from UP foods would be inversely linked to diet cost calculated per $8368 \mathrm{~kJ}^{(15)}$. A secondary aim was to compare percentage energy from UP foods by socio-demographic strata $^{(18)}$. The present hypothesis was that percentage energy from UP foods would be higher among groups of lower education and incomes ${ }^{(18)}$ and living in more disadvantaged neighbourhoods. Processed energy-dense foods of minimal nutritional value often represent the lowest-cost option for the vulnerable low-income consumer ${ }^{(18-20)}$. Given that UP foods are primarily defined by their content of added fat, sugar and salt ${ }^{(19)}$, we expected an inverse correlation between percentage energy from UP foods and dietary nutrient density measures.

\section{Methods}

\section{Study design and participants}

The SOS III was a population-based longitudinal study of adult male and female residents of King, Pierce and Yakima Counties in WA State. Participant recruitment was countyspecific, relying on address-based sampling schemes stratified by three bands of residential property values. For King County, property value ranges were $<\$ 199000, \$ 200000-$ 299000 and $\$ 300000+$, following past SOS III protocols ${ }^{(21)}$. Potential participants were sent pre-notification letters and then contacted by phone to screen for eligibility. Participants were also recruited from lower-income neighbourhoods through community outreach to ensure broad representation by SES and race/ethnicity. Participant recruitment and data collection were conducted in-person by local staff at each research site (from July 2016 to May 2017).

Eligible adults were aged 21-59 years, household gatekeepers, not pregnant or breast-feeding (at the time of data collection), and without any mobility issues. Following initial verbal consent, participants were invited to complete the first in-person visit at local study site or at home (Yakima only). Written consent was provided during the in-person visit before starting the study procedures. Data were collected in English (in all three counties) and Spanish (in Yakima County). All study procedures were approved by the Institutional Review Boards of respective sites. The present analytical sample was based on 755 male and female respondents.

\section{Procedure and study variables}

Computer-assisted health behaviour survey. A computerbased survey administered during an in-person interview was used to collect data on age, sex, race/ethnicity, household income, education, employment, marital status and household size. Data from county tax assessors at the tax parcel level for 2016 were used to estimate residential property value, as additional measure of $\mathrm{SES}^{(21)}$. Estimated monthly household food expenditures at home and away from home were obtained by self-report. At-home food expenditures included grocery purchases, whereas away-from-home food expenditures were on foods consumed outside home (restaurants and cafeteria). Athome and away-from-home expenditures were summed to create total monthly food expenditures variable. This was divided by household size to create total monthly food expenditures per capita.

Dietary intakes data. Dietary intakes data were collected using Fred Hutch FFQ also administered during the in-person interview. The FFQ consists of a list of 126 line-item foods that are visible to the respondent and 378 foods that are not. For purposes of nutrient analysis, each of the 126 line items is represented by a variable number of component foods that are weighted to calculate its energy and nutrient content.

The FFQ component items were aggregated into four NOVA food processing categories: unprocessed, processed, UP and culinary ingredients, using published classification schemes ${ }^{(22)}$. Unprocessed foods have been defined as those fresh, dry or frozen foods that had been subjected to minimal or no processing. The FFQ component foods included fresh meat, fish, fruits (such as apple, banana and apricots), salad, milk, vegetables (broccoli, green beans and potatoes), eggs, legumes and unsalted nuts (raisins and prunes) and seeds. Culinary ingredients were sugar, animal fats (butter) and oils (olive oil, rapeseed oil and maize oil), and salt ${ }^{(22)}$. Adding culinary ingredients (fat, sugar and salt) to wholesome fresh foods transformed them into processed foods. The FFQ component foods classified as processed foods included all kinds of cheese, ham, beer and wine. FFQ foods classified as UP foods included breads, jams and jelly, breakfast cereals, sweet snacks (cookies and cakes), pizza, potato chips or tortilla chips, soft drinks (sodas and fruit drinks), French fries, sauces (ketchup, mayonnaise), desserts (ice cream, frozen yogurt and sherbet) and, frozen meals, juices and soups.

\section{Energy-adjusted individual-level diet cost}

Estimates of individual-level daily diet cost were obtained by joining dietary intake data from FFQ instruments with countyspecific retail prices for 378 FFQ component foods. Retail prices were obtained from large supermarkets in King, Pierce and Yakima counties following standard and published procedures ${ }^{(15,23)}$.

Retail prices converted to dollars per $100 \mathrm{~g}$ edible portion were added to the G-SEL nutrient database. Effectively, food prices per $100 \mathrm{~g}$ were treated in the same way as energy density $(\mathrm{kJ} / 100 \mathrm{~g})$ or nutrient values, also expressed as amounts $(\mathrm{g} / \mathrm{mg}$ per IU) per $100 \mathrm{~g}$ edible portion. Energy and nutrient content of the daily diet were obtained by summing all foods consumed by 
an individual on a given day. In an analogous manner, the estimated cost of the daily diet was obtained by summing the cost of all foods consumed. The G-SEL nutrient composition database was thus composed of forty-five energy and nutrient vectors and a single cost vector. The procedures of estimating diet costs from FFQ have been described previously ${ }^{(16)}$. The procedure has been used in studies conducted in France ${ }^{(17)}$, Spain ${ }^{(24)}$ UK $^{(25)}$ and Japan ${ }^{(26)}$ and has become a part of the epidemiology toolbox. For analytical purpose, this diet cost was divided by energy intake and expressed per $8368 \mathrm{~kJ} / \mathrm{d}$ (2000 kcal/d). Diet cost per d was then converted into monthly diet cost variable.

\section{Percentage energy from ultra-processed foods}

NOVA classification guidelines ${ }^{(1)}$ separate foods into unprocessed, processed, UP and culinary ingredients. Unprocessed foods include fruits, vegetables, grains or meats that had been subjected to minimal or no processing. Culinary ingredients are defined as sugar, animal fats (butter) and vegetable oils, starches, salt, and vinegar. Processed foods are defined as having been manufactured by adding culinary ingredients to wholesome fresh foods. Examples include cheese, ham, salted, smoked, or canned meat, beer and wine. UP foods are defined as industrial creations that contain added fat, sugar and salt as well as ingredients not found in home cooking. Classified as UP foods are commercial breads (refined and whole grain), ready-to-eat breakfast cereals, cakes, sweet snacks, and pizza, French fries, soft drinks, ice cream, and frozen meals and soups.

The NOVA food classification ${ }^{(1)}$ was attached to each of 378 FFQ components foods in the G-SEL nutrient database as described above, to parallel nutrient values. In this way, a processing code was added to each of the 378 foods in the GSEL database. The contribution of UP foods to energy and nutrients was then calculated for each SOS III participant. Dietary share of UP foods was computed by dividing the energy content intake from UP foods category with the total energy intake for individual diet.

\section{Dietary quality measures}

Healthy Eating Index 2015 (HEI-2015) was developed to assess compliance with US 2015 dietary guidelines ${ }^{(27,28)}$. HEI-2015 score reflects an overall diet quality computed using nine adequacy components (total fruit, whole fruit, total vegetables, greens and beans, whole grains, dairy products, total protein, seafood and plant proteins and fatty acids) and four moderation components (refined grains, $\mathrm{Na}$ and saturated fat and added sugars). The HEI-2015 is a continuous score on the scale of 0-100 where higher score reflects higher diet quality.

The Nutrient Rich Food Index $9.3\left(\mathrm{NRF}_{9.3}\right)$ was the second measure of dietary nutrient density ${ }^{(29,30)}$. The $\mathrm{NRF}_{9.3}$ score applied to total diets ${ }^{(31)}$ was based on nine nutrients to encourage (NR9 subscore) and three nutrients to limit (LIM subscore). Reference daily values were based on the US Food and Drug Administration and other standards ${ }^{(30,31)}$. The reference amounts were protein ( $50 \mathrm{~g})$, fibre $(28 \mathrm{~g})$, vitamin A $(900 \mathrm{mg})$, vitamin C (90 mg), vitamin D (20 $\mathrm{g})$, Ca (1300 mg), Fe (18 mg), K $(4700 \mathrm{mg}$ ) and $\mathrm{Mg}(420 \mathrm{mg})$. The maximum recommended values for the LIM component were added sugar ( $50 \mathrm{~g}$ ), saturated fat $(20 \mathrm{~g})$ and $\mathrm{Na}(2300 \mathrm{mg})$. The $\mathrm{NRF}_{9.3}$ was calculated as:

$$
\mathrm{NRF}_{9.3}=(\mathrm{NR} 9-\mathrm{LIM}) \times 100 .
$$

In NR9 calculation, each daily nutrient intake was adjusted for $8368 \mathrm{~kJ}$ and expressed in percentage of daily value. Following past protocol, percentage of daily values were truncated at $100 \%$, so that an excessively high intake of one nutrient could not compensate for the dietary inadequacy of another. In LIM, only the maximum recommended value share in excess of the recommended amount was considered.

\section{Statistical analysis}

The present analysis made use of data from dietary intake assessment at baseline. Responses with missing data on sociodemographic variables, under and over-reporters of FFQ total energy intakes $(<500$ or $>5000 \mathrm{kcal}(<2092$ or $>20920 \mathrm{~kJ}))$ and extreme outliers on diet cost were excluded. The final analytic sample size was 755 individuals.

First, percentage of energy from UP foods was estimated for each participant. Analysis was conducted for the total sample and by socio-demographic group of interest. The mean and standard deviation for monthly diet cost (per $8368 \mathrm{~kJ}$ ) was also calculated by each socio-demographic variable. Second, percentage of UP foods energy was also calculated by each cost indicator. A series of univariate linear regression models using generalised linear estimating equations with robust standard errors were used to test for significance across socio-demographic strata and cost indicators.

Third, percentage energy from UP foods and other dietary quality indicators were compared across tertiles of diet cost and monthly food expenditure. Individuals were classified by tertiles of monthly diet cost (adjusted per $8368 \mathrm{~kJ}$ ). Mean and standard deviation for dietary share of UP foods, energy density, NRF subcomponents (NR9 and LIM) and HEI-2015 were compared across tertiles. Statistical tests of the association between cost tertiles, UP foods energy and diet quality measures were based on ANOVA.

Fourth, the association between UP foods energy and sociodemographic characteristics was tested using multiple-adjusted linear regression models with robust standard errors. UP foods energy was the dependent variable and sex, age, race, education, property value, self-reported food expenditure and diet cost were the independent variables. Model 1 was the multivariate model taking all the variables and covariates into account with the exception of self-reported expenditure. Model 2 was similar to model 1 but with the exception of diet cost. All statistical analyses were conducted using IBM SPSS Statistics for Windows, version 22.0 (IBM Corp. 2013).

\section{Results}

Table 1 shows that the SOS III study sample was mostly female ( $82 \%$ ), married (58.5\%), evenly distributed by age group and with a high proportion of Hispanic participants. Whereas $44 \%$ 
Table 1. Dietary share of ultra-processed foods and monthly diet costs (per $2000 \mathrm{kcal} / \mathrm{d}(8368 \mathrm{~kJ})$ ) by socio-demographic variables (Numbers and percentages; mean values and standard deviations)

\begin{tabular}{|c|c|c|c|c|c|c|c|c|}
\hline \multirow[b]{2}{*}{ Variables } & \multicolumn{2}{|c|}{ Frequency } & \multicolumn{3}{|c|}{$\begin{array}{l}\% \text { Energy content from } \\
\text { ultra-processed foods }\end{array}$} & \multicolumn{3}{|c|}{ Monthly diet cost $/ 2000 \mathrm{kcal}(8368 \mathrm{~kJ})$} \\
\hline & $n$ & $\%$ & Mean & SD & $P$ & Mean & SD & $P$ \\
\hline Overall & 755 & 100 & $59 \cdot 68$ & $10 \cdot 73$ & - & 283.66 & $59 \cdot 41$ & - \\
\hline \multicolumn{9}{|l|}{ Sex } \\
\hline Male & 135 & $17 \cdot 9$ & $58 \cdot 43$ & $10 \cdot 46$ & Ref. & $281 \cdot 34$ & 54.88 & Ref. \\
\hline Female & 620 & $82 \cdot 1$ & $59 \cdot 95$ & $10 \cdot 78$ & $0 \cdot 127$ & $284 \cdot 16$ & $60 \cdot 38$ & 0.594 \\
\hline \multicolumn{9}{|l|}{ Age (years) } \\
\hline $21-40$ & 286 & $37 \cdot 9$ & $60 \cdot 24$ & $11 \cdot 13$ & Ref. & $272 \cdot 32$ & 51.93 & Ref. \\
\hline $41-50$ & 230 & $30 \cdot 5$ & 60.57 & 9.95 & $0 \cdot 721$ & $287 \cdot 07$ & 62.08 & $0.004^{*}$ \\
\hline$\geq 51$ & 239 & $31 \cdot 7$ & $58 \cdot 14$ & $10 \cdot 86$ & $0.029^{*}$ & 293.94 & 63.03 & $<0.0001^{\star}$ \\
\hline \multicolumn{9}{|l|}{ Education } \\
\hline High school or less & 255 & 33.8 & $64 \cdot 12$ & 8.46 & Ref. & $257 \cdot 32$ & $46 \cdot 96$ & Ref. \\
\hline Some college & 166 & $22 \cdot 0$ & $60 \cdot 22$ & $10 \cdot 28$ & $<0.0001^{*}$ & $286 \cdot 20$ & $61 \cdot 13$ & $<0.0001^{*}$ \\
\hline College graduate/graduate school & 334 & $44 \cdot 2$ & $56 \cdot 01$ & $11 \cdot 18$ & $<0.0001^{*}$ & 302.50 & $59 \cdot 74$ & $<0.0001^{\star}$ \\
\hline \multicolumn{9}{|l|}{ Residential property value } \\
\hline Tertile $1(\leq \$ 128675)$ & 252 & 33.4 & 63.81 & 8.42 & Ref. & $257 \cdot 48$ & $46 \cdot 02$ & Ref. \\
\hline Tertile 2 (\$128 676-\$290 866) & 253 & 33.5 & 58.97 & $11 \cdot 10$ & $<0.0001^{*}$ & $286 \cdot 34$ & 57.66 & $<0.0001^{\star}$ \\
\hline Tertile 3 ( $\geq \$ 290867)$ & 250 & $33 \cdot 1$ & $56 \cdot 22$ & 11.09 & $<0.0001^{*}$ & $307 \cdot 32$ & $62 \cdot 66$ & $<0.0001^{\star}$ \\
\hline \multicolumn{9}{|l|}{ Race/ethnicity } \\
\hline Non-Hispanic White & 366 & 48.5 & $57 \cdot 67$ & $10 \cdot 96$ & Ref. & $300 \cdot 89$ & 58.53 & Ref. \\
\hline Hispanic & 307 & $40 \cdot 7$ & $63 \cdot 27$ & 8.82 & $<0.0001^{*}$ & $260 \cdot 42$ & 51.63 & $<0.0001^{\star}$ \\
\hline Other & 82 & $10 \cdot 9$ & $55 \cdot 14$ & $12 \cdot 21$ & 0.082 & $293 \cdot 73$ & $62 \cdot 15$ & 0.338 \\
\hline \multicolumn{9}{|l|}{ Marital status } \\
\hline Married & 442 & 58.5 & 59.38 & $10 \cdot 81$ & 0.371 & 286.54 & 59.57 & 0.108 \\
\hline Single & 313 & 41.5 & 60.09 & $10 \cdot 68$ & Ref. & 279.54 & 59.04 & Ref. \\
\hline
\end{tabular}

Ref., reference.

* Statistical significance at $P<0.05$ and $P<0.0001$.

of the sample were college graduates, $34 \%$ did not complete high school.

Mean percentage of dietary energy from UP foods was $59.7 \%$. There were significant differences by socio-demographic strata. Higher percentage energy from UP foods was associated with younger adults $(P<0.029)$, Hispanic participants compared with non-Hispanic Whites $(P<0.0001)$, lower education $(P<0.0001)$ and lower residential property values $(P<0.0001)$. There were no significant effects of sex or marital status.

For each population subgroup, mean percentage energy from UP foods was inversely associated with FFQ-based estimates of energy-adjusted diet cost in $\$ /$ month. Higher diet costs were associated with older adults, non-Hispanic Whites, college education and higher residential property values. There were no significant effects of sex or marital status.

Table 2 shows the relation between percentage energy from UP foods and two indicators of food spending: energy-adjusted diet costs and self-reported food expenditures, at home and total. Both variables were split into tertiles. An increase in diet cost was associated with a decline in UP foods energy from 65 to $53 \%$. An increase in food expenditures was associated with a decline in UP foods energy from 63 to $56 \%$.

Fig. 1 shows the inverse relation between percentage of energy from UP foods and deciles of energy-adjusted cost. The bottom decile of diet cost $(\$ 216 \cdot 4 /$ month $)$ was associated with $67.5 \%$ energy from UP foods; the top decile ( $\$ 369.9 /$ month) was associated with only $48.7 \%$ energy from UP foods.

Table 3 shows multiple indicators of diet quality by tertiles of diet cost. As expected, the $\mathrm{NRF}_{9.3}$ dietary nutrient density score and its NR9 and LIM subcomponents showed a dose-response
Table 2. Dietary share of ultra-processed foods by food spending indicators

(Numbers and percentages; mean values and standard deviations)

\begin{tabular}{|c|c|c|c|c|c|}
\hline \multirow[b]{2}{*}{ Variables } & \multicolumn{2}{|c|}{ Frequency } & \multicolumn{3}{|c|}{$\begin{array}{l}\% \text { Energy content from ultra- } \\
\text { processed foods }\end{array}$} \\
\hline & $n$ & $\%$ & Mean & SD & $P$ \\
\hline Overall & 755 & 100 & $59 \cdot 68$ & $10 \cdot 73$ & - \\
\hline \multicolumn{6}{|c|}{ Diet cost per $2000 \mathrm{kcal}$ (8368 kJ) (\$/month) } \\
\hline$\leq \$ 252.7$ & 252 & 33.4 & $65 \cdot 23$ & $9 \cdot 30$ & Ref. \\
\hline$\geq \$ 252.8$ to $\leq 299.9$ & 252 & 33.4 & $60 \cdot 88$ & 8.77 & $<0.0001^{*}$ \\
\hline$\geq \$ 300$ & 251 & $33 \cdot 2$ & $52 \cdot 88$ & $10 \cdot 22$ & $<0.0001^{*}$ \\
\hline \multicolumn{6}{|c|}{ Monthly food expenditures at home } \\
\hline$\leq \$ 100$ & 276 & $36 \cdot 6$ & $62 \cdot 84$ & 9.97 & Ref. \\
\hline$\geq \$ 101$ to $\leq 175$ & 237 & 31.4 & 59.45 & $10 \cdot 11$ & $<0.0001^{*}$ \\
\hline$\geq \$ 176$ & 242 & $32 \cdot 1$ & $56 \cdot 28$ & $11 \cdot 12$ & $<0.0001^{*}$ \\
\hline \multicolumn{6}{|c|}{ Total monthly food expenditures } \\
\hline$\leq \$ 144$ & 252 & 33.4 & 62.63 & $10 \cdot 08$ & Ref. \\
\hline$\geq \$ 145$ to $\leq 250$ & 271 & 35.9 & 59.85 & $10 \cdot 07$ & $0.002^{*}$ \\
\hline$\geq \$ 251$ & 232 & 30.7 & $56 \cdot 26$ & $11 \cdot 21$ & $<0.0001^{*}$ \\
\hline
\end{tabular}

Ref., reference.

* Statistical significance at $P<0.01$ and $P<0.0001$.

relation with diet cost. Dietary energy density was also a function of diet cost. Going from the bottom to the top tertile of diet cost, energy density of the diet, calculated based on foods and energetic beverages only, declined from 1.31 to $1.08 \mathrm{kcal} / \mathrm{g}(5.48$ to $4.52 \mathrm{~kJ} / \mathrm{g}$ ). The LIM nutrient density subscore (based on saturated fat, added sugar and $\mathrm{Na}$ ) decreased from 99.70 to 86.59 on going from the bottom to the top quartiles of diet cost. The NR9 based on protein, fibre, vitamins and minerals increased from $654 \cdot 26$ to $736 \cdot 38$. Total $\mathrm{NRF}_{9.3}$ scores increased as well. 


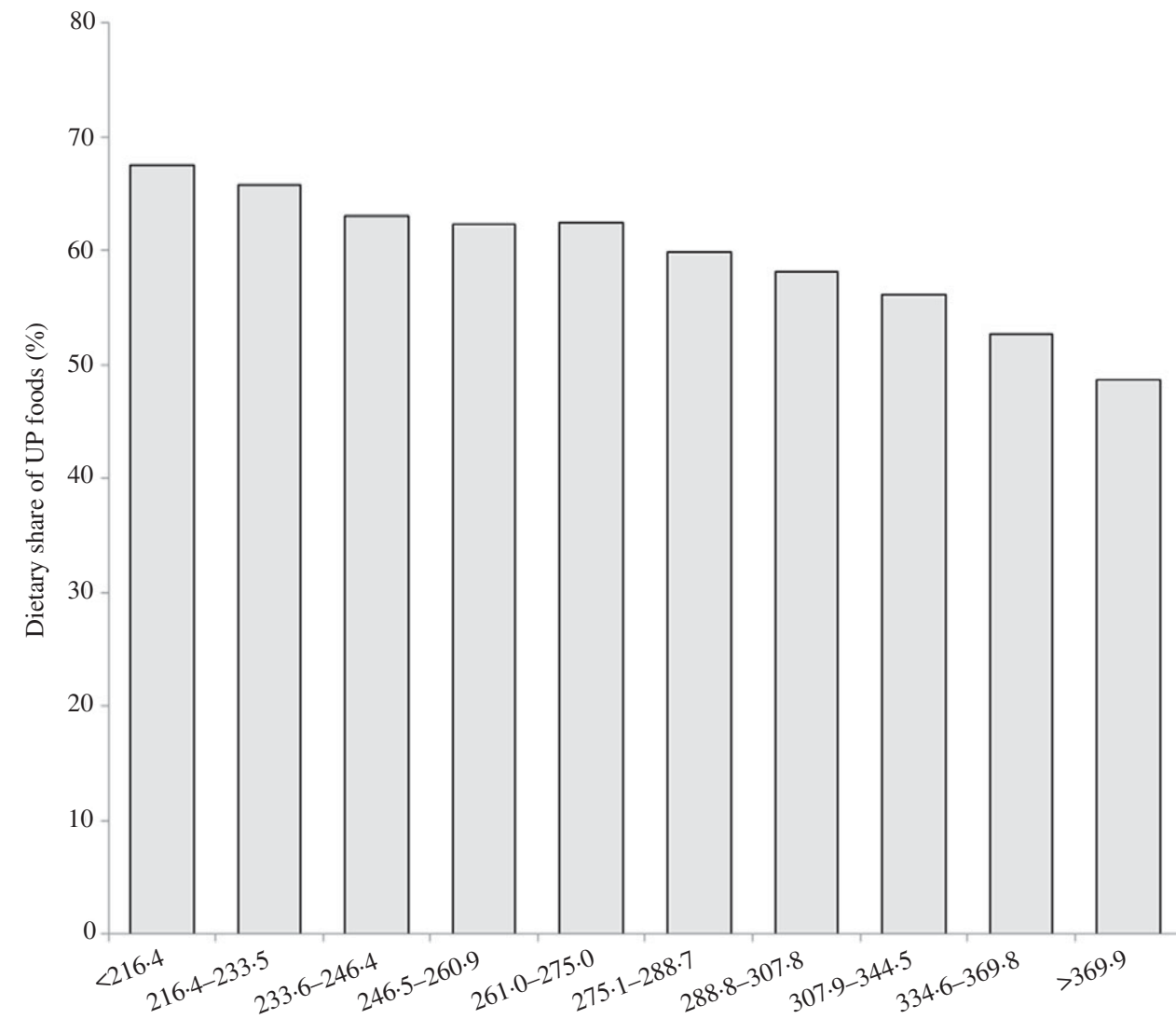

Deciles of diet cost per $2000 \mathrm{kcal}(8368 \mathrm{~kJ})$

Fig. 1. Dietary share of ultra-processed (UP) foods by deciles of diet cost (\$) per $2000 \mathrm{kcal}(8368 \mathrm{~kJ})$.

Table 3. Indicators of diet quality across tertiles (T) of estimated monthly diet cost (adjusted per $2000 \mathrm{kcal}(8368 \mathrm{~kJ})$ ) and self-reported monthly food expenditure

(Mean values and standard deviations)

\begin{tabular}{|c|c|c|c|c|c|c|c|}
\hline & \multicolumn{7}{|c|}{ Tertiles of estimated monthly diet cost (adjusted per $2000 \mathrm{kcal}(8368 \mathrm{~kJ})$ ) } \\
\hline & \multicolumn{2}{|c|}{$\mathrm{T} 1(n 252)$} & \multicolumn{2}{|c|}{ T2 ( $n$ 252) } & \multicolumn{2}{|c|}{ T3 $(n$ 251) } & \multirow[b]{2}{*}{$P$} \\
\hline & Mean & SD & Mean & SD & Mean & SD & \\
\hline Energy density & 1.31 & 0.25 & 1.22 & 0.21 & 1.08 & 0.18 & $<0.0001^{*}$ \\
\hline $\mathrm{NRF}_{9.3}$ & 553.08 & 105.47 & 591.92 & 88.30 & 649.80 & $77 \cdot 11$ & $<0.0001^{*}$ \\
\hline LIM & $99 \cdot 70$ & 43.01 & $96 \cdot 82$ & $42 \cdot 73$ & 86.59 & 35.09 & $0.001^{*}$ \\
\hline NR9 & 654.26 & $70 \cdot 89$ & $688 \cdot 74$ & 64.84 & $736 \cdot 38$ & 67.69 & $<0.0001^{*}$ \\
\hline \multirow[t]{4}{*}{ HEI-2015 } & 62.57 & 9.91 & $67 \cdot 18$ & $9 \cdot 70$ & 71.55 & $7 \cdot 87$ & $<0.0001^{*}$ \\
\hline & \multicolumn{7}{|c|}{ Tertiles of total monthly food expenditure } \\
\hline & \multicolumn{2}{|c|}{$\mathrm{T} 1$ ( $n$ 252) } & \multicolumn{2}{|c|}{ T2 ( $n$ 271) } & \multicolumn{2}{|c|}{ T3 ( $n$ 232) } & \\
\hline & Mean & SD & Mean & SD & Mean & SD & $P$ \\
\hline Energy density & $1 \cdot 20$ & 0.23 & 1.22 & 0.23 & $1 \cdot 18$ & 0.25 & 0.138 \\
\hline $\mathrm{NRF}_{9.3}$ & 588.73 & $104 \cdot 25$ & 598.14 & $90 \cdot 56$ & 608.54 & $102 \cdot 72$ & 0.090 \\
\hline LIM & 97.06 & 41.84 & 91.51 & $36 \cdot 20$ & 94.82 & 44.48 & 0.293 \\
\hline NR9 & $687 \cdot 28$ & 76.57 & 689.65 & $72 \cdot 20$ & 703.35 & 77.91 & $0.042^{*}$ \\
\hline HEI-2015 & 65.23 & 9.53 & $66 \cdot 80$ & $10 \cdot 04$ & 69.45 & 9.68 & $<0.0001^{*}$ \\
\hline
\end{tabular}

$\mathrm{NRF}_{9.3}$, Nutrient Rich Food Index 9.3; LIM, nutrients to limit; NR9, nine nutrients to encourage; HEI-2015, Healthy Eating Index 2015.

* Statistically significant $P$ values. 
Table 4. Linear regression analysis showing association of socio-demographic indicators with percentage energy from ultra-processed foodst (Mean values and $95 \%$ confidence intervals)

\begin{tabular}{|c|c|c|c|c|c|c|}
\hline & \multicolumn{3}{|c|}{ Model 1: Diet cost per $2000 \mathrm{kcal}(8368 \mathrm{~kJ})$ (\$/month) } & \multicolumn{3}{|c|}{ Model 2: Total food expenditures per capita ( $\$ /$ month) } \\
\hline & Mean difference in diet cost & $P$ & $95 \% \mathrm{Cl}$ & Mean difference in diet cost & $P$ & $95 \% \mathrm{Cl}$ \\
\hline \multicolumn{7}{|l|}{ Education } \\
\hline High school or less & Ref. & & & Ref. & & \\
\hline Some college & -1.07 & 0.331 & $-3.24,1.09$ & $-1 \cdot 75$ & $0 \cdot 156$ & $-4 \cdot 18,0.67$ \\
\hline College graduate/graduate school & $-4 \cdot 12$ & $0.001^{*}$ & $-6.52,-1.73$ & -4.97 & $<0.0001^{*}$ & $-7 \cdot 63,-2 \cdot 31$ \\
\hline \multicolumn{7}{|l|}{ Residential property value } \\
\hline Tertile $1(\leq \$ 128675)$ & Ref. & & & Ref. & & \\
\hline Tertile 2 (\$128 676-\$290 866) & $-1 \cdot 29$ & $0 \cdot 153$ & $-3.06,0.48$ & -1.91 & 0.071 & $-3 \cdot 99,0 \cdot 17$ \\
\hline Tertile $3(\geq \$ 290867)$ & -2.07 & 0.067 & $-4 \cdot 29,0.15$ & $-3 \cdot 11$ & $0.017^{\star}$ & $-5.67,-0.55$ \\
\hline \multicolumn{7}{|c|}{ Total monthly food expenditure per capita } \\
\hline$\leq \$ 144$ & & & & Ref. & & \\
\hline$\geq \$ 145$ to $\leq 250$ & & & & $-1 \cdot 20$ & $0 \cdot 168$ & $-2.90,0.50$ \\
\hline$\geq \$ 251$ & & & & -3.01 & $0.007^{\star}$ & $-5 \cdot 20,-0.83$ \\
\hline \multicolumn{7}{|c|}{ Diet cost per $2000 \mathrm{kcal}(8368 \mathrm{~kJ})$ (\$/month) } \\
\hline$\leq \$ 252.7$ & Ref. & & & & & \\
\hline$\geq \$ 252.8$ to $\leq 299.9$ & $-3 \cdot 78$ & $<0.0001^{*}$ & $-5 \cdot 32,-2 \cdot 22$ & & & \\
\hline$\geq \$ 300$ & $-10 \cdot 89$ & $<0.0001^{*}$ & $-12 \cdot 66,-9 \cdot 12$ & & & \\
\hline
\end{tabular}

* Statistically significant at $P<0.01, P<0.0001$.

$\dagger$ Both models controlled for all variables in the table as well as sex, age, race/ethnicity and county.

The mean HEI score increased by 9 points on going from the lowest quartile to the highest quartile of diet cost $(62.57 v$. 71.55). Table 3 also shows relation of diet quality indicators with tertiles of self-reported food expenditure. Similar to diet cost, mean HEI score also increased significantly points on going from the lowest quartile to the highest quartile of food expenditure (65.23v. 69.45).

The results of multiple regression analysis between education, residential property values, two measures of food spending and percentage energy from UP food are shown in Table 4. Models were adjusted for variables in the table, as well as for sex, age and race/ethnicity. In model 1 , higher diet cost was also associated with an $11 \%$ less percentage energy from UP foods $(\beta=-10 \cdot 89,95 \% \mathrm{CI}-12 \cdot 66,-9 \cdot 12)$. Having college education or higher was associated with $4 \%$ less energy from UP foods $(\beta=-4 \cdot 12,95 \%$ CI $-6 \cdot 52,-1 \cdot 73)$ as compared with high school or less. In adjusted model 2 , higher food expenditures and college education were associated with a reduction in percentage energy from UP foods of 3 and $5 \%$, respectively.

\section{Discussion}

The mean percentage of dietary energy from UP foods in the SOS III sample was $59.7 \%$, close to the value of $58 \%$ previously calculated from 24-h dietary recalls in the much larger and nationally representative National Health and Nutrition Examination Survey (2007-2012) ${ }^{(1,32)}$. However, there were significant differences by subgroup. Percentage energy from UP foods varied by food expenditures, diet cost and participant SES.

The inverse relation between percentage energy from UP foods and participant education and incomes has been noted before. Past analyses of dietary intakes in National Health and Nutrition Examination Survey 2007-2012 also showed that the consumption of UP foods decreased with age, education and income $^{(1,32)}$. In Canada, UP foods accounted for $47.7 \%$ of energy, with higher percentages reported among groups with lower education $(51.7 \%)^{(33)}$. In France, UP foods contributed $35.9 \%$ of total energy intake ${ }^{(34)}$, with higher UP consumption associated with younger age and lower education ${ }^{(34)}$. In the $\mathrm{UK}^{(35)}$, data from the National Diet and Nutrition Survey (2008-2012) showed lower consumption of minimally processed foods among lower SES groups, but the consumption of UP foods did not vary by occupational social class, an unexpected finding.

Based on published papers, the direction of the social gradient for UP foods appears to be reversed on low- and middle-income countries. First, socio-economic gradients in diet quality are now apparent in both high-income and in low- and middle-income countries ${ }^{(36)}$. Those associations also hold for children and adolescents ${ }^{(37)}$. When it comes to UP foods, data from Brazil( ${ }^{(38)}$ and from Chile ${ }^{(39)}$ have shown that higher percentage energy from UP foods was associated with higher, rather than with lower, SES. In Mexico too ${ }^{(40)}$, higher consumption of UP foods was associated with higher SES and higher education of head of household. Clearly, there are major sociodemographic differences in UP food consumption patterns between the low- and middle-income countries in Latin and in South America and high-income countries such as the USA, Canada, the UK and France.

Given the opposing social gradients in UP foods energy, it is surprising that no study on the relation between UP foods and health has addressed the disparity in food prices and diet costs. In the present study, we used two measures of food spending: food expenditures obtained through self-report and estimated individual-level diet costs. The present method of attaching retail food prices to dietary intakes data from FFQ or from 24-h recalls has now become a standard procedure in nutritional epidemiology ${ }^{(41)}$. In effect, retail costs per $100 \mathrm{~g}$, edible portion, are treated as another nutrient vector. It is important to note that the calculated diet cost reflects the intrinsic monetary cost of the diet and not actual food expenditures. However, both methods produced comparable results. 
Efforts to reduce percentage energy from UP foods at the population have made little mention of the economics of food choice. A study from Spain ${ }^{(42)}$ found that an isoenergetic substitution of UP food with unprocessed or minimally processed foods was associated with a significant drop in mortality. At least $28 \%$ of lives would be saved (on paper) if the current consumption of UP foods could be reduced from the highest quartile (68\% of energy) to the lowest quartile ( $48 \%$ of energy) $)^{(42)}$. Whether such a reduction would be associated with a higher per energy diet cost to the affected consumer was not mentioned.

The present analyses can provide some answers. In the present sample, a reduction in the consumption of UP foods from $67.5 \%$ of energy ( 1 st decile) to $48 \%$ of energy (10th decile) was associated with a mean increase in estimated diet costs from $\$ 216.4$ (1st decile) to $\$ 369.9$ (10th decile). A $\$ 153$ increase in monthly diet costs would translate into $\$ 7368$ per year for a family of four. Clearly, there are economic reasons for why lowerincome people select low-cost energy-dense foods as opposed to the recommended 'prudent' options. What is not clear is that the association between social class and diet quality ${ }^{(16,17)}$ can be manipulated at will. In the present data, a $10 \%$ drop in energy from UP foods was also associated with an additional $\$ 45169.7$ increase in mean residential property values at the tax parcel level.

For the most part, studies have tended to view the consumption of UP foods as a matter of individual choice. Researchers have taken the position that continuing promotion of fresh and minimally processed foods should be the main policy to improve global public health ${ }^{(13)}$. Suggestions for public health interventions generally ran towards consumer education, improved labelling, taxation and marketing restrictions ${ }^{(13)}$. It may be time to focus attention on why people turn to low-cost energy-dense foods in times of economic hardship and stress.

The present confirmation that percentage energy from UP foods is associated with lower food spending and lower energy-adjusted diet costs has some troubling implications for nutritional epidemiology. What observational studies have taught us is that diets associated with lower non-communicable disease risk cost more ${ }^{(16,43,44)}$, whereas diets associated with higher non-communicable disease risk generally cost less ${ }^{(16-18)}$. In other studies, foods associated with weight loss tended to be more expensive ${ }^{(45)}$, whereas foods associated with weight gain were relatively cheap ${ }^{(45)}$. Diets higher in added sugars and saturated fats that have been linked with a higher risk of heart disease ${ }^{(46)}$, obesity and diabetes ${ }^{(47)}$ generally cost less than diets that are unprocessed and nutrient rich.

The present study had limitations. First, the estimates of diet quality indicators were based on FFQ which may lead to bias. However, it is a useful tool to make comparisons across subjects and has been widely used in nutritional epidemiological studies. Second, diet cost estimates do not represent actual expenditures made by the study sample. This limitation has been corrected by asking participants to self-report actual grocery and eating out expenditures. Third, ambiguity in the definition of NOVA classification may have resulted in some misclassification, though this has been minimised by employing two independent researchers to assign food items. Lastly, the present study was based on cross-sectional data; hence, associations observed between
SES, diet cost and other diet quality indicator cannot be causally interpreted.

Despite these limitations, the present study has several strengths. This is one of the very few studies to explore the low cost of UP foods in relation to diet quality metrics. The study included the analysis of individual food intake for a cohort of adults from different geographic locations of WA State using a validated FFQ to measure food consumption over a 12-month period.

\section{Conclusion}

Percentage energy from UP foods and measures of food spending were inversely linked. Low-cost foods of high energy density and low nutritional value that are selected by lower-income groups have long been associated with adverse health outcomes. Studies on socio-economic determinants of health would do well to take food prices and affordability into account.

\section{Acknowledgements}

This work was supported by NIH NIDDKR01 DK076608.

The authors' responsibilities were as follows: S. G. was responsible for study conception, data analyses and drafting the manuscript. A. D. aided in study conception and drafting the manuscript. C. R., J. B., L. K., A. C., A. A. and J. M. contributed to drafting and revising the manuscript.

A. D. is the original developer of the Naturally Nutrient Rich and the Nutrient Rich Food (NRF) indices. That work was supported at the time by the Nutrient Rich Coalition. Coalition members were The Beef Checkoff Program through the National Cattlemen's Beef Association, California Avocado Commission, California Kiwifruit, California Strawberry Commission, Egg Nutrition Center, Florida Department of Citrus, Grain Foods Foundation, National Dairy Council, National Pork Board, United States Potato Board, Wheat Foods Council and Wild Blueberry Association of North America. A. D. has received grants, contracts and honoraria from entities both public and private with an interest in nutrient profiling and assessing nutrient density of foods. Other authors have no conflicts of interest to report.

\section{References}

1. Martinez Steele E, Baraldi LG, Louzada ML, et al. (2016) Ultraprocessed foods and added sugars in the US diet: evidence from a nationally representative cross-sectional study. BMJ Open 6, e009892.

2. Hall KD, Ayuketah A, Brychta R, et al. (2019) Ultra-processed diets cause excess calorie intake and weight gain: an inpatient randomized controlled trial of ad libitum food intake. Cell Metab 30, 67-77.e3.

3. Asfaw A (2011) Does consumption of processed foods explain disparities in the body weight of individuals? The case of Guatemala. Health Econ 20, 184-195.

4. Louzada ML, Baraldi LG, Steele EM, et al. (2015) Consumption of ultra-processed foods and obesity in Brazilian adolescents and adults. Prev Med 81, 9-15.

5. Srour B, Fezeu LK, Kesse-Guyot E, et al. (2020) Ultraprocessed food consumption and risk of type 2 diabetes among 
participants of the NutriNet-Santé prospective cohort. IAMA Intern Med 180, 283-291.

6. Martinez Steele E, Juul F, Neri D, et al. (2019) Dietary share of ultra-processed foods and metabolic syndrome in the US adult population. Prev Med 125, 40-48.

7. Mendonca RD, Lopes AC, Pimenta AM, et al. (2017) Ultraprocessed food consumption and the incidence of hypertension in a Mediterranean cohort: the Seguimiento Universidad de Navarra Project. Am J Hypertens 30, 358-366.

8. Adjibade M, Julia C, Allès B, et al. (2019) Prospective association between ultra-processed food consumption and incident depressive symptoms in the French NutriNet-Santé cohort. BMC Med 17, 78.

9. Gomez-Donoso C, Sanchez-Villegas A, Martinez-Gonzalez MA, et al. (2020) Ultra-processed food consumption and the incidence of depression in a Mediterranean cohort: the SUN Project. Eur J Nutr 59, 1093-1103.

10. Sandoval-Insausti H, Blanco-Rojo R, Graciani A, et al. (2020) Ultra-processed food consumption and incident frailty: a prospective cohort study of older adults. J Gerontol A Biol Sci Med Sci 75, 1126-1133.

11. Fiolet T, Srour B, Sellem L, et al. (2018) Consumption of ultraprocessed foods and cancer risk: results from NutriNet-Sante prospective cohort. BMJ 360, k322.

12. Schnabel L, Kesse-Guyot E, Alles B, et al. (2019) Association between ultraprocessed food consumption and risk of mortality among middle-aged adults in France. JAMA Intern Med 179, 490-498.

13. Rico-Campà A, Martínez-González MA, Alvarez-Alvarez I, et al. (2019) Association between consumption of ultra-processed foods and all cause mortality: SUN prospective cohort study. BMJ 365, 11949.

14. Monteiro CA, Cannon G, Levy RB, et al. (2019) Ultra-processed foods: what they are and how to identify them. Public Health Nutr 22, 936-941.

15. Gupta S, Hawk T, Aggarwal A, et al. (2019) Characterizing ultraprocessed foods by energy density, nutrient density, and cost. Front Nutr 6, 70.

16. Aggarwal A, Monsivais P, Cook AJ, et al. (2011) Does diet cost mediate the relation between socioeconomic position and diet quality? Eur J Clin Nutr 65, 1059-1066.

17. Darmon N \& Drewnowski A (2015) Contribution of food prices and diet cost to socioeconomic disparities in diet quality and health: a systematic review and analysis. Nutr Rev 73, 643-660.

18. Drewnowski A \& Specter SE (2004) Poverty and obesity: the role of energy density and energy costs. Am J Clin Nutr 79, 6-16.

19. Drewnowski A, Gupta S \& Darmon N (2020) An overlap between "Ultraprocessed" foods and the preexisting nutrient rich foods index? Nutr Today 55, 75-81.

20. Darmon N \& Drewnowski A (2008) Does social class predict diet quality? Am J Clin Nutr 87, 1107-1117.

21. Drewnowski A, Aggarwal A, Cook A, et al. (2016) Geographic disparities in Healthy Eating Index scores (HEI-2005 and 2010) by residential property values: findings from Seattle Obesity Study (SOS). Prev Med 83, 46-55.

22. Monteiro CA, Cannon G, Moubarac JC, et al. (2018) The UN Decade of Nutrition, the NOVA food classification and the trouble with ultra-processing. Public Health Nutr 21, 5-17.

23. Monsivais P, McLain J \& Drewnowski A (2010) The rising disparity in the price of healthful foods: 2004-2008. Food Policy 35, 514-520.

24. Lopez CN, Martinez-Gonzalez MA, Sanchez-Villegas A, et al (2009) Costs of Mediterranean and western dietary patterns in a Spanish cohort and their relationship with prospective weight change. J Epidemiol Community Health 63, 920-927.
25. Cade J, Upmeier H, Calvert C, et al. (1999) Costs of a healthy diet: analysis from the UK Women's Cohort Study. Public Health Nutr 2, 505-512.

26. Murakami K, Sasaki S, Okubo H, et al. (2007) Monetary costs of dietary energy reported by young Japanese women: association with food and nutrient intake and body mass index. Public Health Nutr 10, 1430-1439.

27. Krebs-Smith SM, Pannucci TE, Subar AF, et al. (2018) Update of the Healthy Eating Index: HEI-2015. J Acad Nutr Diet 118, 1591-1602

28. U.S. Department of Agriculture, U.S. Department of Health (2015) 2015-2020 Dietary Guidelines for Americans, 8th ed. Washington, DC. http://health.gov/dietaryguidelines/2015/ guidelines/ (accessed June 2020).

29. Fulgoni VL 3rd, Keast DR \& Drewnowski A (2009) Development and validation of the nutrient-rich foods index: a tool to measure nutritional quality of foods. $J$ Nutr 139 , 1549-1554.

30. Drewnowski A (2010) The Nutrient Rich Foods Index helps to identify healthy, affordable foods. Am J Clin Nutr 91, 1095s1101s.

31. Rehm CD \& Drewnowski A (2017) Replacing American breakfast foods with ready-to-eat (RTE) cereals increases consumption of key food groups and nutrients among US children and adults: results of an NHANES Modeling Study. Nutrients 9, 1010

32. Baraldi LG, Martinez Steele E, Canella DS, et al. (2018) Consumption of ultra-processed foods and associated sociodemographic factors in the USA between 2007 and 2012: evidence from a nationally representative cross-sectional study. BMJ Open 8, e020574.

33. Moubarac JC, Batal M, Louzada ML, et al. (2017) Consumption of ultra-processed foods predicts diet quality in Canada. Appetite 108, 512-520.

34. Julia C, Martinez L, Allès B, et al. (2018) Contribution of ultraprocessed foods in the diet of adults from the French NutriNetSanté study. Public Health Nutr 21, 27-37.

35. Adams J \& White M (2015) Characterisation of UK diets according to degree of food processing and associations with sociodemographics and obesity: cross-sectional analysis of UK National Diet and Nutrition Survey (2008-12). Int J Behav Nutr Phys Act 12, 160.

36. Mayén AL, Marques-Vidal P, Paccaud F, et al. (2014) Socioeconomic determinants of dietary patterns in low- and middle-income countries: a systematic review. Am J Clin Nutr 100, 1520-1531.

37. Hinnig PF, Monteiro JS, de Assis MAA, et al. (2018) Dietary patterns of children and adolescents from high, medium and low human development countries and associated socioeconomic factors: a systematic review. Nutrients 10, 436.

38. Simoes BDS, Barreto SM, Molina M, et al. (2018) Consumption of ultra-processed foods and socioeconomic position: a cross-sectional analysis of the Brazilian Longitudinal Study of Adult Health (ELSA-Brasil). Cad Saude Publica 34, e00019717.

39. Cediel G, Reyes M, da Costa Louzada ML, et al. (2018) Ultraprocessed foods and added sugars in the Chilean diet (2010). Public Health Nutr 21, 125-133.

40. Marron-Ponce JA, Sanchez-Pimienta TG, Louzada M, et al. (2018) Energy contribution of NOVA food groups and sociodemographic determinants of ultra-processed food consumption in the Mexican population. Public Health Nutr 21, 87-93.

41. Rehm CD, Monsivais P \& Drewnowski A (2015) Relation between diet cost and Healthy Eating Index 2010 scores among adults in the United States 2007-2010. Prev Med 73, 70-75. 
42. Blanco-Rojo R, Sandoval-Insausti H, López-Garcia E, et al. (2019) Consumption of ultra-processed foods and mortality: a National prospective cohort in Spain. Mayo Clin Proc $\mathbf{9 4}$ 2178-2188.

43. Monsivais P \& Drewnowski A (2009) Lower-energy-density diets are associated with higher monetary costs per kilocalorie and are consumed by women of higher socioeconomic status. $J$ Am Diet Assoc 109, 814-822.

44. Rao M, Afshin A, Singh G, et al. (2013) Do healthier foods and diet patterns cost more than less healthy options? A systematic review and meta-analysis. BMJ Open 3, e004277.
45. Mozaffarian D, Hao T, Rimm EB, et al. (2011) Changes in diet and lifestyle and long-term weight gain in women and men. $N$ Engl J Med. 364, 2392-2404.

46. Hu FB, Stampfer MJ, Rimm E, et al. (1999) Dietary fat and coronary heart disease: a comparison of approaches for adjusting for total energy intake and modeling repeated dietary measurements. Am J Epidemiol 149, 531-540.

47. Schulze MB, Manson JE, Ludwig DS, et al. (2004) Sugarsweetened beverages, weight gain, and incidence of type 2 diabetes in young and middle-aged women. JAMA 292, 927-934. 